\title{
Efficacy of radiotherapy for gastric bleeding associated with advanced gastric cancer
}

\author{
Joongyo Lee ${ }^{1}$, Hwa Kyung Byun ${ }^{1}$, Woong Sub Koom¹, Yong Chan Lee ${ }^{2}$ and Jinsil Seong ${ }^{1 *}$
}

\begin{abstract}
Background: Gastric bleeding negatively impacts the quality of life of patients with unresectable advanced gastric cancer and is frequently lethal. We investigated the efficacy of RT for palliation of gastric bleeding from gastric cancer and identified an optimal radiotherapy (RT) strategy.

Methods: The study analyzed 57 patients submitted to palliative RT for gastric bleeding associated with gastric cancer between January 2009 and February 2019. Changes in hemoglobin (Hb) levels were analyzed based on measurements taken before and immediately, 1 month, and 2 months after RT. Re-bleeding after RT was identified as either $\mathrm{Hb}$ level dropping to $<7.0 \mathrm{~g} / \mathrm{dL}$ or the administration of a blood transfusion after RT.

Results: The median biologically effective dose $(\alpha / \beta=10)$ was $37.5 \mathrm{~Gy}$ (range 23.6-58.5). The most common regimen was $25 \mathrm{~Gy}$ in five fractions. The mean $\mathrm{Hb}$ levels before, immediately after, 1 month, and 2 months after RT (6.6, $9.7,10.3$, and $9.7 \mathrm{~g} / \mathrm{dL}$, respectively) were significantly higher than that before RT (all $p<0.001$ ). No significant differences in re-bleeding rates were observed according to total dose, fractional dose, and fraction number. Gastric tumor response evaluated by computed tomography within 2 months after RT showed partial responses were more frequent in patients achieving bleeding control $(25.0 \%$ vs. $10.8 \%, p=0.023)$ and overall survival was significantly improved for bleeding control within 3 months after RT (median, 15.4 vs. 10.0 weeks, $p=0.048$ ).
\end{abstract}

Conclusions: RT was an effective modality for gastric bleeding control in gastric cancer, which can be achieved with a short course scheme with five fractions.

Keywords: Gastric cancer, Radiotherapy, Bleeding, Palliative treatment

\section{Background}

Gastric cancer accounted for $5.7 \%$ of all cancers worldwide in 2018, with Korea having the highest incidence; furthermore, gastric cancer is one of the most common causes of cancer-related death [1]. More than 10\% of gastric cancer patients are associated with bleeding at the same time when they were first diagnosed, and more than half of them were major bleeding [2]. $5 \%$ of upper

\footnotetext{
${ }^{*}$ Correspondence: jsseong@yuhs.ac

${ }^{1}$ Department of Radiation Oncology, Yonsei Cancer Center, Yonsei University College of Medicine, 50-1 Yonsei-ro, Seodaemun-gu, 03722 Seoul, Republic of Korea

Full list of author information is available at the end of the article

This article belongs to the Topical Collection: Clinical Radiation Oncology.
}

gastrointestinal bleedings are caused by tumor mass, with primary gastric cancer the most common cause of tumor bleeding [3, 4]. Bleeding caused by gastric cancer not only degrades patient quality but can also lead to life-threatening conditions due to hematological instability. This deterioration of patient condition also interferes with cancer treatment; thus, failure to control bleeding can lead to a poor prognosis [5].

Treatments for bleeding control include endoscopic therapy, transcatheter arterial embolization, and radiotherapy (RT). Endoscopic therapy showed hemostasis rates of $73-100 \%$, making it excellent for bleeding control; however, the re-bleeding rates were approximately $40 \%$ [5-7]. In particular, predicted endoscopic hemostasis failure was higher for large bleeding lesions $(>2 \mathrm{~cm})$ 
and non-exposed vessel bleeding [8]. Transcatheter arterial embolization also provides rapid control of massive bleeding. However, the re-bleeding rate after the first hemostasis is $41-66 \%$, worse than that for endoscopic therapy $[9,10]$. RT is also effective for tumor bleeding, with reported control rates of $50-89 \%$ [11-13]. RT is non-invasive compared to other treatments; hence, it can be used in patients with poor physical condition. However, the optimal palliative RT strategy has not been wellestablished due to a lack of conclusive data.

This study investigated the efficacy of RT for palliation of gastric cancer-associated gastric bleeding and suggested an optimal RT strategy.

\section{Methods}

\section{Patients}

The study analyzed 57 patients who received palliative RT for gastric cancer-associated gastric bleeding between January 2009 and February 2019 at Yonsei Cancer Center. In all patients, gastric bleeding was confirmed by esophagogastroduodenoscopy. Patients who neither had RT/ gastric bleeding-related records or complete RT were excluded. We evaluated 57 patients who were eligible for our study.

This study was approved by the Severance Hospital institutional review board(No. 4-2020-1305), and the requirement for informed consent was waived because of the retrospective nature of this study. All methods were carried out in accordance with relevant guidelines and regulations.

\section{Radiotherapy}

All patients underwent palliative RT using externalbeam RT. The gross tumor volume was defined as the gross tumor lesion as seen on computed tomography (CT). Internal target volume was defined as considering the respiratory movement in the gross tumor volume, and four-dimensional CT with free breathing was used to account for the respiratory movement. Clinical target volume was defined as internal target volume plus $0.3 \mathrm{~cm}$ margins. Planning target volume was defined as clinical target volume plus $0.3 \mathrm{~cm}$ margins for set-up uncertainty. Dose was prescribed to planning target volume. The biologically effective dose (BED) was calculated to compare different RT fractionation regimens. BED was calculated according to the following equation: $\mathrm{BED}=\mathrm{nD}[1+\mathrm{D} /$ $(\alpha / \beta)$ ], where $n=$ fraction number, $D=$ dose per fraction, and $\alpha / \beta=10$ for gastric cancer.

\section{Response evaluation}

Re-bleeding after palliative RT was defined as either a decrease in the hemoglobin $(\mathrm{Hb})$ level to $<7.0 \mathrm{~g} / \mathrm{dL}$ or blood transfusion after RT with or without an $\mathrm{Hb}$ level $<7.0 \mathrm{~g} / \mathrm{dL}$. The changes in $\mathrm{Hb}$ levels were analyzed at various time points: the baseline $\mathrm{Hb}$ within 1 month before initiating $\mathrm{RT}, \mathrm{Hb}$ at RT completion, at 1 month, and 2 months after RT completion.

We also assessed whether our patients no longer had clinical symptoms (melena, hematemesis) after RT. These clinical symptoms were confirmed through the medical record, and it was mainly checked whether the symptoms were relieved one month after the end of RT.

In patients who underwent endoscopy after RT, we checked whether the bleeding improved on the endoscopic findings.

To evaluate the response of gastric tumors by RT, CT images were performed within 1 to 2 months after the end of RT. Tumor response was determined according to Response Evaluation Criteria in Solid Tumors (RECIST), version 1.1 [14]. Treatment-related toxicities were graded according to the Criteria for Adverse Events, version 5.0 [15].

\section{Statistical analysis}

Cumulative re-bleeding rate (CRR) was defined as the time from $\mathrm{RT}$ completion to $\mathrm{Hb}$ level dropping below $7.0 \mathrm{~g} / \mathrm{dL}$ or receiving a blood transfusion after RT with or without $\mathrm{Hb}$ level $<7.0 \mathrm{~g} / \mathrm{dL}$. Overall survival (OS) was defined as the time from RT completion to death or last patient contact. CRR and OS were analyzed using the Kaplan-Meier method and log-rank test. Univariate and multivariate analyses for CRR were performed with the Cox proportional hazards model.

Repeated-measures analysis of variance (ANOVA) was performed to assess the changes in $\mathrm{Hb}$ level at each time point after RT (the baseline $\mathrm{Hb}$ within 1 month before initiating RT, $\mathrm{Hb}$ at RT completion, at 1 month, and 2 months after RT completion).

The Pearson $\chi^{2}$ test was used to identify the relationship between the gastric tumor response and bleeding control after RT.

P-values lower than 0.05 were considered statistically significant. Statistical analysis was performed using IBM SPSS Statistics for Windows, version 23.0 (IBM Corp., Armonk, NY, USA).

\section{Results}

\section{Patient and treatment characteristics}

The baseline characteristics of all patients are listed in Table 1 . The median age was 61 years (range, 33-87 years). Fifty-two patients (91.2\%) and 5 patients $(8.8 \%)$ were diagnosed with adenocarcinoma and signet ring cell carcinoma, respectively. Fifty patients $(87.7 \%)$ had distant metastasis at the time of RT and 7 (12.3\%) patients had locally advanced disease. 
Table 1 Patient and tumor characteristics

\begin{tabular}{ll}
\hline Characteristic & N (\%) \\
\hline Age (median years, range) & $61(33-87)$ \\
Sex & \\
Male & $35(61.4)$ \\
Female & $22(38.6)$ \\
Performance status (Eastern Cooperative Oncology Group) & \\
1 & $26(45.6)$ \\
2 & $21(36.8)$ \\
3 & $8(14.0)$ \\
4 & $2(3.5)$ \\
Histopathology & \\
Adenocarcinoma & $52(91.2)$ \\
Signet ring cell carcinoma & $5(8.8)$ \\
Stage (American Joint Committee on Cancer 8th revision) & \\
IIA & $1(1.8)$ \\
IIB & $2(3.5)$ \\
IIIA & $2(3.5)$ \\
IIIB & $2(3.5)$ \\
IV & $50(87.7)$ \\
Chemotherapy & \\
Before radiotherapy & \\
During radiotherapy & $43(75.4)$ \\
After radiotherapy & $10(17.5)$ \\
Endoscopic hemostasis therapy before radiotherapy & $27(47.4)$ \\
No & \\
Yes & $11(19.3)$ \\
Baseline hemoglobin (median g/dL, range) & $46(80.7)$ \\
\hline
\end{tabular}

All but one patient (98.2\%) received three-dimensional conformal RT (3D-CRT). The remaining one patient received intensity modulated RT (IMRT). The median total applied dose was $\mathrm{BED}_{10} 37.5$ Gy (range 23.6$58.5 \mathrm{~Gy}$ ). All patients have completed scheduled RT. The median dose per fraction was 4.0 Gy (range 1.8-5.0 Gy) and a median of 5 fractions (range, 4-25 fractions). The most common dose fractionation regimen was $25 \mathrm{~Gy}$ in five fractions (29.8\%), followed by 20 Gy in 5 fractions (24.6\%) and 30 Gy in 10 fractions (22.8\%) (Fig. 1).

Forty-three patients $(75.4 \%)$ received standard dose of chemotherapy before RT, 10patients (17.5\%) during RT, and 27 patients (47.4\%) after RT. Ten patients received irinotecan plus folinic acid/fluorouracil, 11 patients received oxaliplatin plus folinic acid/fluorouracil, 11 patients received capecitabine plus oxaliplatin, and 11 patients received S-1 plus cisplatin. There were 46 patients $(80.7 \%)$ who underwent endoscopic hemostatic treatment before RT.

\section{Changes in symptoms and transfusion}

Forty-three patients (75.4\%) showed subjective symptom improvements one month after the end of RT; melena in 27 patients, hematemesis in 10 patients, and both in 6 patients. The remaining 14 patients $(24.6 \%)$ continued to have subjective symptoms after RT. Among these 14 patients, eight continued to have melena, two continued bleeding as observed through the Levin Tube, and four had recurrent hematemesis.

All but one patient received blood transfusions before $\mathrm{RT}$, and all of them received transfusions within 1 week prior to initiation of RT. There were 50 patients $(87.7 \%)$ who received blood transfusions during RT. After RT, 21 patients (36.8\%) received no further transfusions. The median interval from the end of RT to receiving transfusion was 2.9 weeks (range, $0.3-38.9$ weeks) in 36 patients who received transfusion even after RT.

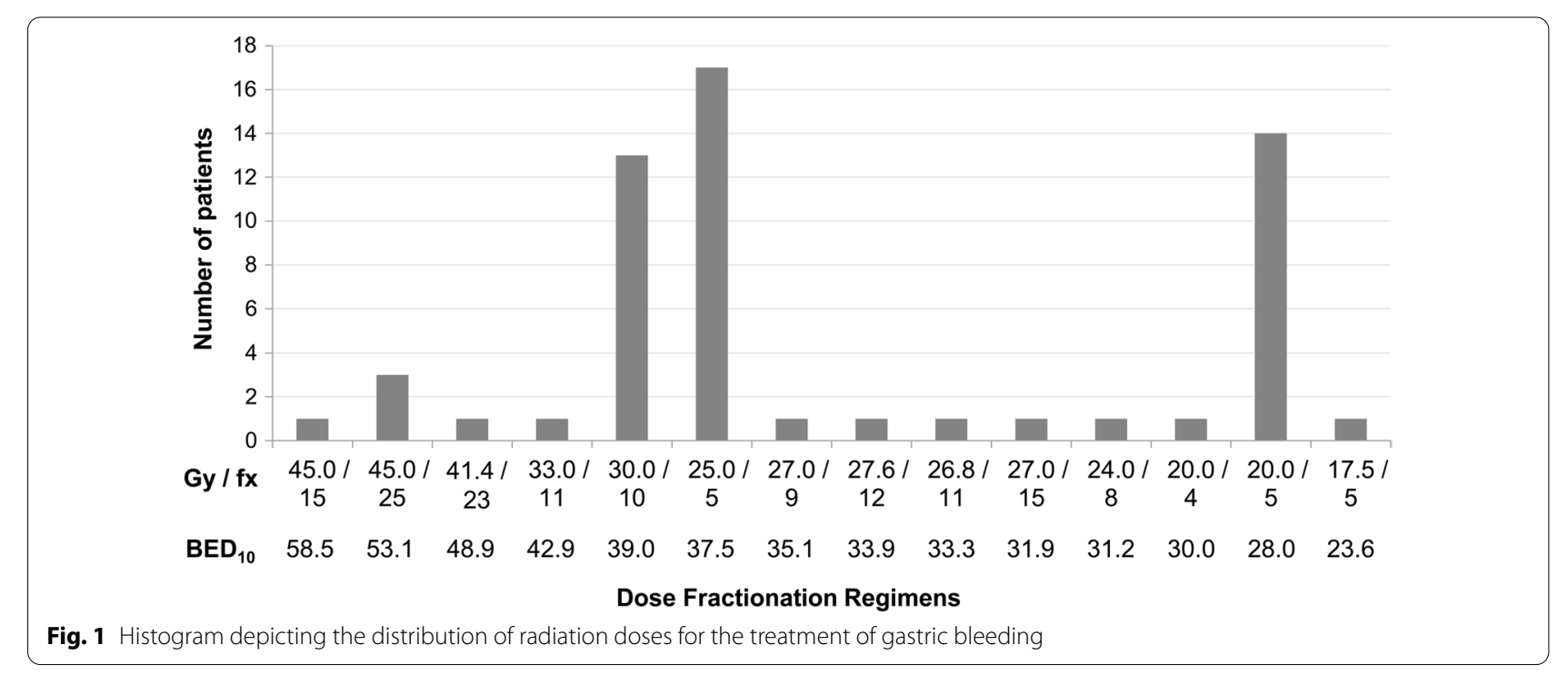




\section{Endoscopic assessment}

Twenty-one patients (36.8\%) underwent endoscopy within 2 months after RT completion. Of these, 14 (66.7\%) were confirmed to stop bleeding completely. Five (23.8\%) had minor bleeding like oozing, and the other 2 (9.5\%) had no response. No patients were found to have new bleeding in another point other than the treated.

\section{Changes in $\mathrm{Hb}$ level}

The mean of the baseline $\mathrm{Hb}$ level within 1 month before RT was $6.6 \pm 1.3 \mathrm{~g} / \mathrm{dL}$, while the mean levels immediately, 1 month, and 2 months after RT were $9.7 \pm 1.0 \mathrm{~g} /$ $\mathrm{dL}, 10.3 \pm 1.1 \mathrm{~g} / \mathrm{dL}$, and $9.7 \pm 1.6 \mathrm{~g} / \mathrm{dL}$, respectively. The changes in $\mathrm{Hb}$ levels and mean patient $\mathrm{Hb}$ levels are shown in Fig. 2. Comparison of the mean of the baseline $\mathrm{Hb}$ level within 1 month before RT to the mean values at each time point (immediately, 1 month, and 2 months after RT) showed significant increases for all ( $\mathrm{p}<0.001$, respectively).

Thirty-five patients $(61.4 \%)$ had the baseline $\mathrm{Hb}$ level within 1 month before RT below $7.0 \mathrm{~g} / \mathrm{dL}$. All patients had $\mathrm{Hb}$ levels above $7.0 \mathrm{~g} / \mathrm{dL}$ immediately and 1 month after RT. At 2 months after RT completion, only two patients had $\mathrm{Hb}$ levels below $7.0 \mathrm{~g} / \mathrm{dL}$.

Of the 35 patients with the baseline $\mathrm{Hb}$ level within 1 month before RT below $7.0 \mathrm{~g} / \mathrm{dL}, 14$ (38.9\%) had levels below $7.0 \mathrm{~g} / \mathrm{dL}$ at least once during the follow-up period after RT completion. In contrast, of the 22 patients with the baseline $\mathrm{Hb}$ level within 1 month before RT above

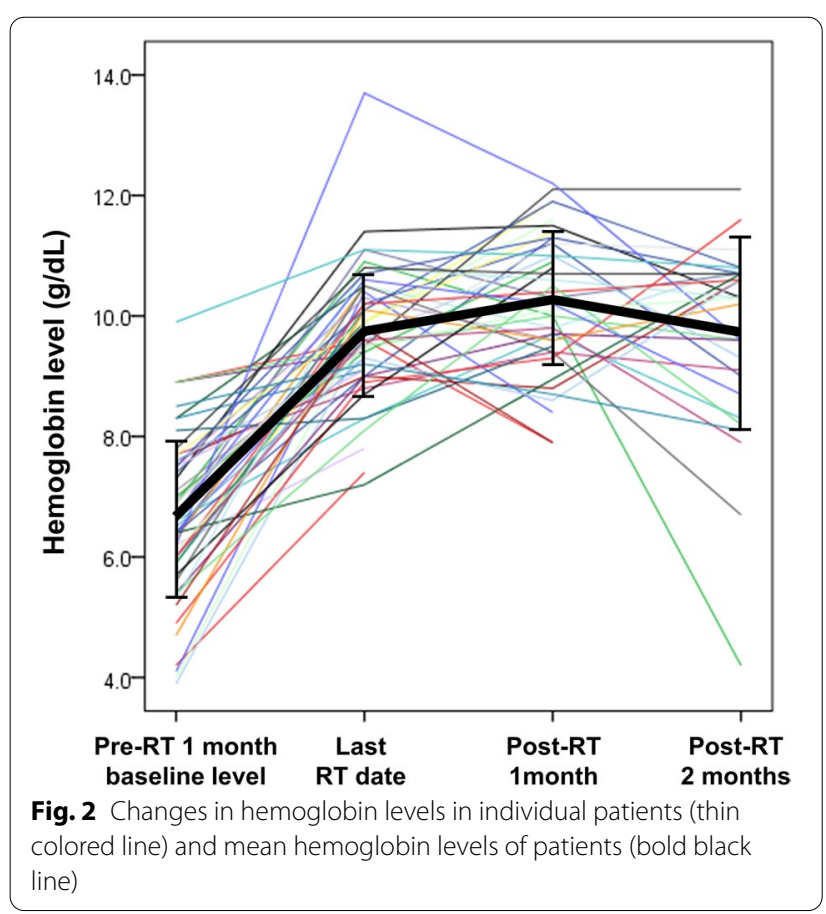

$7.0 \mathrm{~g} / \mathrm{dL}, 5$ (23.8\%) had Hb levels below $7.0 \mathrm{~g} / \mathrm{dL}$ at least once during the follow-up period after RT.

\section{Re-bleeding free rate and toxicity}

The median bleeding-free duration after RT was 6.4 weeks (range 0.3-237.7). CRR at 3 months after RT was $60.2 \%$ (Fig. 3a). CRR was analyzed according to median value of several factors in RT but showed no significant differences for total $\mathrm{BED}_{10} 37.5$ Gy (3 months, CRR $46.4 \%$ vs. $69.0 \%, \mathrm{p}=0.134$ ), fraction dose $4 \mathrm{~Gy}$ (3 months, CRR $67.7 \%$ vs. $54.8 \%, \mathrm{p}=0.348$ ), or fraction number 5 (3 months, CRR $52.9 \%$ vs. $70.8 \%, \mathrm{p}=0.303$ ) (Fig. 3). In univariate analysis, younger age (hazard ratio $0.97,95 \%$ confidence interval $0.95-0.99, \mathrm{p}=0.010$ ) and signet ring cell carcinoma histology (hazard ratio 4.46, 95\% confidence interval $1.62-12.26, p=0.004$ ) were identified poor predictive factors for CRR. However, multivariate analysis showed no independent risk factors associated with CRR (Additional file 1).

The gastric tumor response was evaluated in 37 patients by CT scan within 2 months after RT. Four of the $37(10.8 \%)$ patients had gastric tumor progression despite RT, while 24 (64.9\%) had stable disease and nine (24.3\%) had a partial response. Partial responses were observed more frequently in patients with controlled bleeding (25.0\% vs. $10.8 \%, \mathrm{p}=0.023)$ (Table 2 ).

Among reported treatment-related toxicities, 28 (49.1\%) and $2(3.5 \%)$ patients reported grade 1 and 2 toxicity, respectively. No grade 3 or higher toxicities were reported.

\section{Survival}

Over a median follow-up duration of 13.3 weeks (range 0.7-237.7), 53 patients died (Fig. 4a). Patients whose bleeding was controlled within 3 months after RT completion showed a significantly improved OS $(\mathrm{p}=0.048)$ (Fig. 4b), at 15.4 weeks in 25 patients without re-bleeding vs. 10.0 weeks in 32 patients with re-bleeding.

\section{Discussion}

The results of this study showed that palliative RT is an effective modality for gastric bleeding control in gastric cancer. Although the $\mathrm{Hb}$ level before RT was low (mean, $6.6 \mathrm{~g} / \mathrm{dL}$ ), the level after RT increased to more than $9.7 \mathrm{~g} / \mathrm{dL}$. A bleeding-free duration of 6.4 weeks was achieved with palliative RT without no grade 3 or 4 toxicities. Tumor response was significantly better in patients without re-bleeding and OS was significantly higher in patients whose bleeding was controlled within 3 months after RT completion.

Previous studies showed that RT is an effective modality for gastric bleeding control in gastric cancer. Since there is no established dose regimen for palliative 

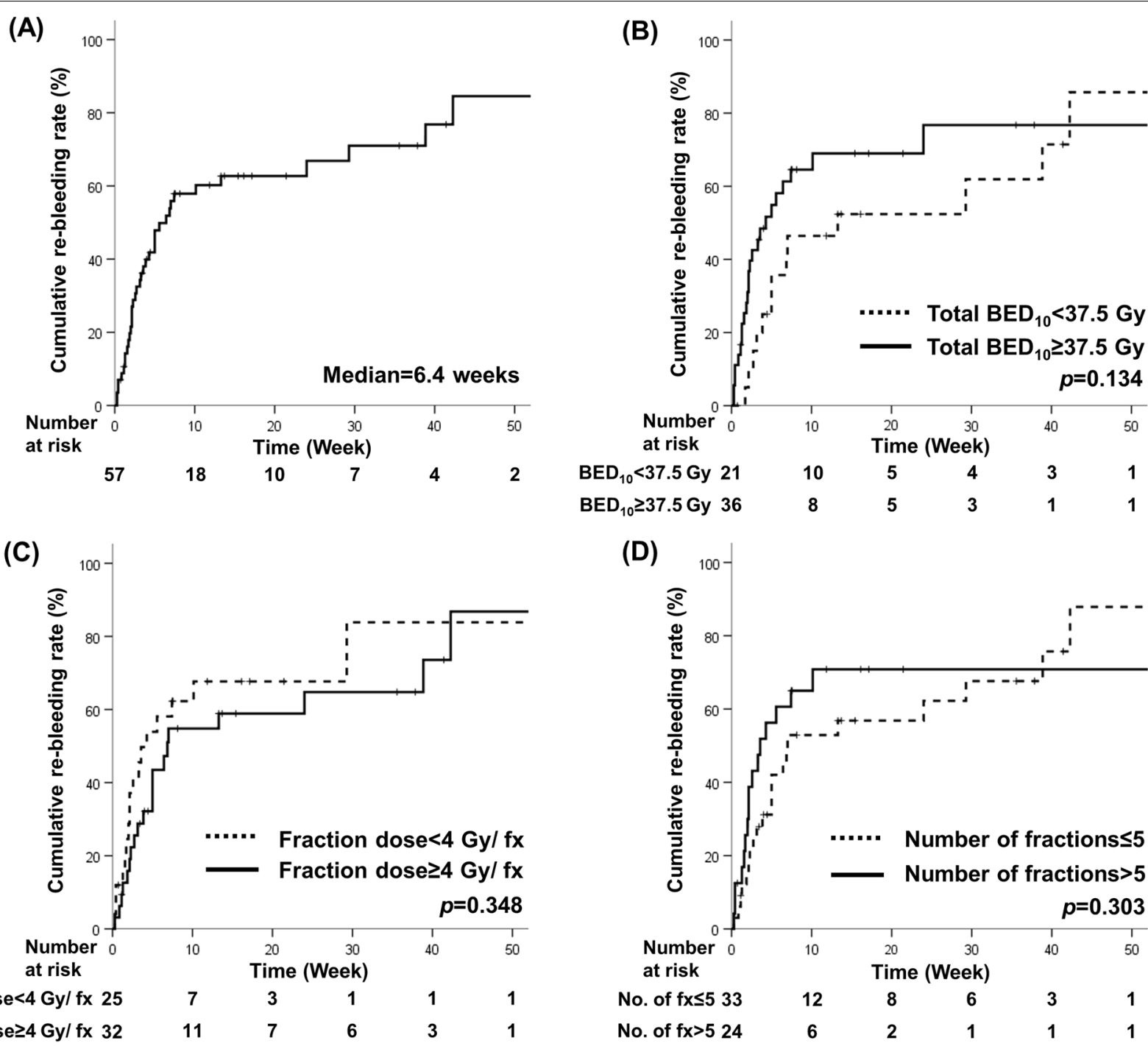

Fig. 3 Cumulative re-bleeding rates for $\mathbf{a}$ all patients and by $\mathbf{b}$ total dose, $\mathbf{c}$ dose per fraction, and $\mathbf{d}$ number of fractions

Table 2 The relationship between bleeding control and tumor response

\begin{tabular}{lll}
\hline Tumor response & $\begin{array}{l}\text { Number of controlled } \\
\text { patients (\%) }\end{array}$ & $\begin{array}{l}\text { Number of non- } \\
\text { controlled patients } \\
\text { (\%) }\end{array}$ \\
\hline Partial response & $5(25.0)$ & $4(10.8)$ \\
Stable disease & $4(20.0)$ & $20(54.1)$ \\
Progressive disease & $0(0.0)$ & $4(10.8)$ \\
Non-evaluated & $11(55.0)$ & $9(24.3)$ \\
Total & 20 & 37 \\
\hline
\end{tabular}

$\mathrm{RT}$, these studies administered various regimens, with fraction doses ranging from 1.8 to $8 \mathrm{~Gy}$ and total doses from 6 to $60 \mathrm{~Gy}$, corresponding to $\mathrm{BED}_{10}$ of 7.2-50.8 Gy
[11-13, 16-19]. Few studies have compared differences in treatment outcomes by fraction dose or numbers. Sapienza et al. showed that the fraction number $(>5$ vs. $\leq 5)$ was not significantly associated with bleeding control [20]. In line with previous reports, our study showed no differences in re-bleeding rates according to fraction dose and number.

Several studies have assessed the correlation between total dose and bleeding controls. One systematic review suggested similar bleeding control effects between low and high BED regimens [21]. In contrast, several studies suggested that higher BED regimens are more effective $[12,16,22]$, with $\mathrm{BED}_{10}$ over $36-41$ Gy showing significantly better local control. In our study, patients were administered various regimens, with total dose $\mathrm{BED}_{10}$ 


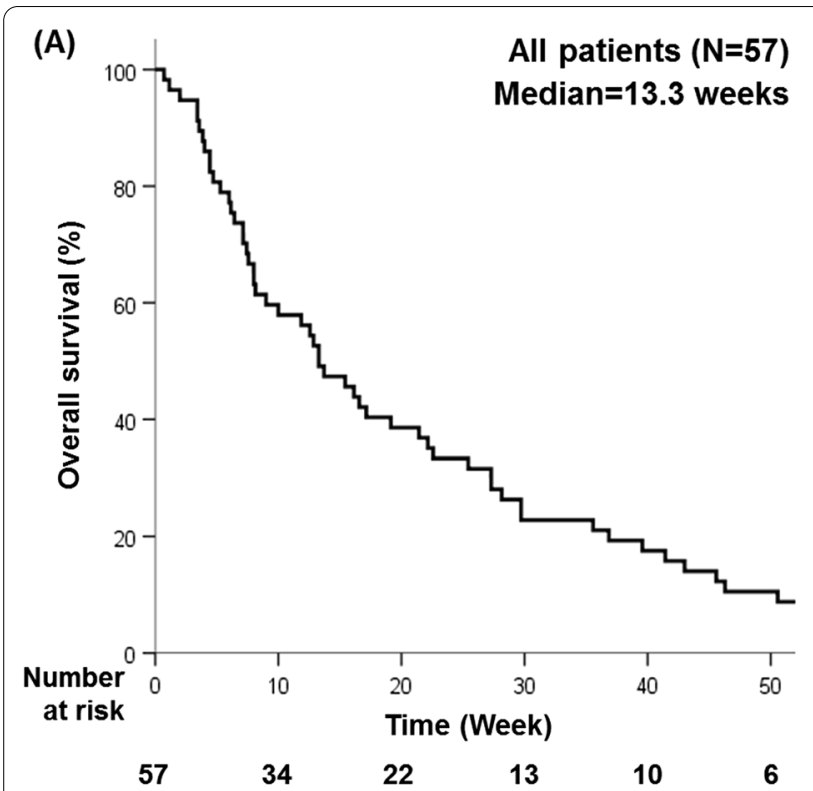

Fig. 4 Overall survival for (a) all patients and (b) by response to radiotherapy

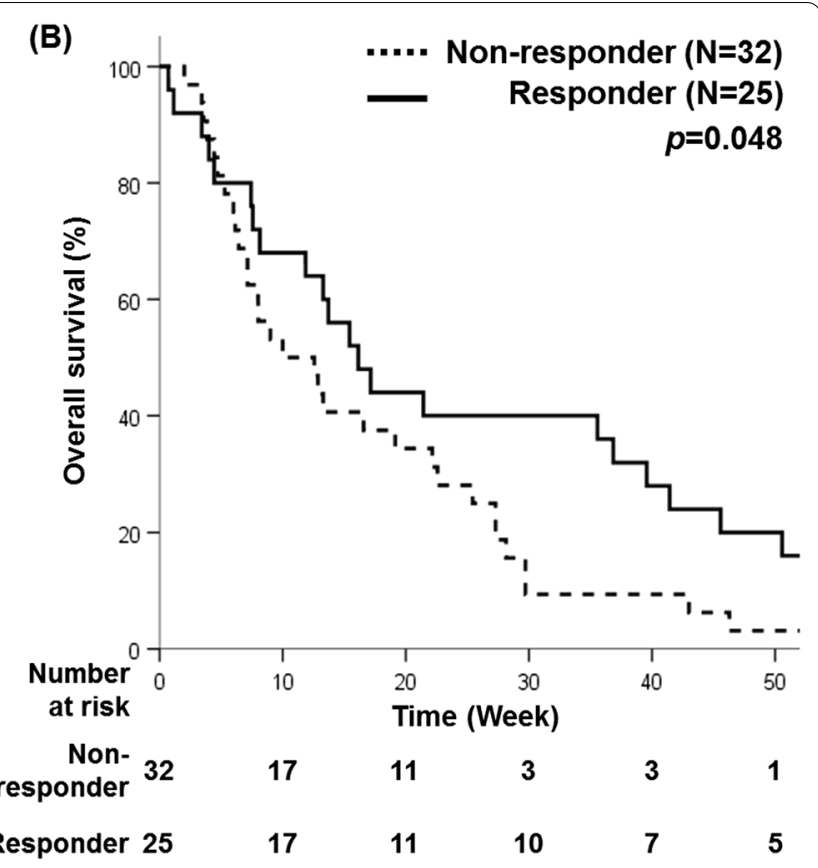

of 23.6-58.5 Gy and fraction doses of 1.8-5.0 Gy. While short-course schemes were preferred for better compliance, protracted courses were selected for patients with large-volume tumors due to concerns regarding toxicity. However, efficacy appeared similar regardless of the fractionation scheme, without toxicity. Therefore, short fractionation regimens with high fractional doses may be reasonable in patients with poor performance status or limited life expectancy and those requiring urgent symptom control. However, for large tumor volumes, it may be better to flexibly administer 30 Gy in 10 -fraction regimens.

Due to the difficulty in defining objective parameters, no standard has yet been established for evaluation of the effect of bleeding control after RT. The most obvious method is to check for hemostasis directly through endoscopic examinations, but quite a number of patients with gastric bleeding have failed to perform post-RT endoscopic examinations due to reasons such as poor condition. In our study, $63.2 \%$ of patients failed to perform endoscopy after RT. Like previous reports, we also used clinical symptoms (melena and hematemesis) to evaluate the hemostatic effect of RT $[12,16,23]$ and observed clinical symptom relief in $75.4 \%$ of cases. Other studies evaluated the response to RT by reviewing the pre- and post-RT Hb levels as well as the reduction in numbers of transfused units or volume of transfused blood after $\mathrm{RT}[24,25]$. $\mathrm{Hb}$ is an objective measure of bleeding; we also showed a significant increase in mean $\mathrm{Hb}$ level after
RT. However, Hb level does not directly reflect acute gastric bleeding and the individual baseline $\mathrm{Hb}$ levels varied widely according to underlying comorbidities and chemotherapy. Therefore, single $\mathrm{Hb}$ measurements may be undesirable as a standard evaluation tool for assessing treatment results. In addition, the number of blood transfusions does not directly reflect bleeding control because of its subjectivity.

Our study proposed two criteria for evaluating rebleeding. First, we observed whether the $\mathrm{Hb}$ level dropped below $7.0 \mathrm{~g} / \mathrm{dL}$ after RT. This cutoff is considered a threshold value in restrictive transfusion strategies recommended for upper gastrointestinal bleeding [26]. In our study, no patients had $\mathrm{Hb}$ levels below $7.0 \mathrm{~g} / \mathrm{dL}$ until one month after RT and only two patients received blood transfusions because their $\mathrm{Hb}$ levels dropped below $7.0 \mathrm{~g} / \mathrm{dL}$ at 2 months after RT. Second, we observed if the bleeding was confirmed or blood transfusion was administrated even when $\mathrm{Hb}$ levels did not fall below $7.0 \mathrm{~g} / \mathrm{dL}$. Our criteria aimed to include both $\mathrm{Hb}$ level and transfusion in bleeding control evaluation and we defined re-bleeding as meeting one of the two criteria, different from the definitions used in other studies.

In this study, the $\mathrm{Hb}$ level at the immediately end of RT was significantly higher than the lowest $\mathrm{Hb}$ level within 1 month before RT (Fig. 2). This might be related to that most of our patients received transfusions within 1 week prior to initiation of RT and during RT. However, it is noteworthy that the number of patients 
receiving transfusions after RT has significantly decreased. In addition, the $\mathrm{Hb}$ level continued to rise until a month after the end of RT, which suggests bleeding control through RT. Therefore, RT seems to keep the $\mathrm{Hb}$ elevation effect of transfusions as long as possible and to further eliminate additional transfusions.

We also analyzed the association between re-bleeding and OS. The reported duration of response varied greatly, with a median ranging from 1.5 to 11.4 months [21]. Lee et al. also proposed the use of mean $\mathrm{Hb}$ level and reduction value in transfusion units within 3 months after RT [23]. According to our data, patients whose bleeding was controlled within 3 months after RT completion showed significantly improved OS.

One patient had a baseline $\mathrm{Hb}$ concentration of $12-15 \mathrm{~g} / \mathrm{dL}$, which dropped to $9.9 \mathrm{~g} / \mathrm{dL}$. Bleeding was confirmed by endoscopy. After RT, the Hb level increased to $11 \mathrm{~g} / \mathrm{dL}$. Although this patient did not have significant anemia initially, they received RT due to the significant drop in $\mathrm{Hb}$ level from baseline. As such, RT can be administered flexibly at physicians' discretion even when $\mathrm{Hb}$ level criteria are not met. Another patient had a drop in $\mathrm{Hb}$ level to $4.2 \mathrm{~g} / \mathrm{dL}$ at 2 months post-RT, which was the baseline $\mathrm{Hb}$ level observed in our study. This patient had a diffuse gastric cancer lesion on the entire stomach wall and, thus, received RT to the whole stomach, with a dose of $30 \mathrm{~Gy}$ in 10 fractions. The initial $\mathrm{Hb}$ level was $6.9 \mathrm{~g} / \mathrm{dL}$, which increased to $10.0 \mathrm{~g} / \mathrm{dL}$ at $1 \mathrm{month}$ post-RT. However, at 2 months post-RT, the level decreased to $4.2 \mathrm{~g} / \mathrm{dL}$, with melena re-occurrence. Thus, reirradiation of $20 \mathrm{~Gy}$ in 10 fractions was administered, with no toxicity above grade 2. Bleeding control was also successful, with melena disappearing and $\mathrm{Hb}$ maintained at over $9.0 \mathrm{~g} /$ $\mathrm{dL}$ until 1 month post-RT. Thus, reirradiation is also an acceptable option when the first palliative attempt fails.

Due to its retrospective nature, this study has some limitations. The RT schemes were varied according to physician's preference although some tendency existed using a short-course scheme in case large tumor size or poor condition of the patients. So there might be selection bias. Therefore, in the future, it seems necessary to plan a prospective study to reduce treatment-related errors by specifying a prescription scheme of RT. Moreover, post-RT additional treatment involving chemotherapy, which might have affected prognosis, couldn't be fully analyzed. Further study with larger population is needed to clarify this issue. Finally, quality survey such as European Organization for Research Treatment of Cancer (EORTC) QLQ-C30 [27], which could provide more objective evaluation, was not implemented in this study due to retrospective nature. To compensate this, we reviewed each case in detail and checked the symptoms at a consistent time point after the end of RT.

\section{Conclusions}

In conclusion, RT was an effective and well-tolerated modality for gastric bleeding control in gastric cancer regardless of the fractionation regimen, resulting in significantly increased $\mathrm{Hb}$ levels. In practical terms, the use of a short-course scheme with five fractions is a suitable option for patients with poor performance status or limited life expectancy, as well as those requiring urgent symptom control.

\section{Abbreviations \\ RT: Radiotherapy; CT: Computed tomography; BED: Biologically effective dose; $\mathrm{Hb}$ : Hemoglobin; RECIST: Response Evaluation Criteria in Solid Tumors; CRR: Cumulative re-bleeding rate; OS: overall survival; ANOVA: Analysis of variance; 3D-CRT: Three-dimensional conformal radiotherapy; IMRT: Intensity modu- lated radiotherapy; EORTC: European Organization for Research Treatment of Cancer.}

\section{Supplementary Information}

The online version contains supplementary material available at https://doi. org/10.1186/s13014-021-01884-5.

Additional file 1. Supplementary Table 1. Univariate and multivariate analysis for cumulative re-bleeding rate.

\section{Acknowledgements \\ None. \\ Authors' contributions \\ $J S$ and JL conceived and designed the study. JS and JL performed the study. $W K$ and $J L$ analyzed the data. $H B, Y L$, and JS contributed materials and analysis tools. JS, JL, and HB prepared all figures and tables, and composed the main manuscript. All authors reviewed the manuscript.}

\section{Funding}

This study was supported by Dong-A research fund (Grant Number 2018-31-0904).

\section{Availability of data and materials}

The datasets used and/or analyzed during the current study are available from the corresponding author on reasonable request.

\section{Declarations}

Ethics approval and consent to participate

Not applicable.

\section{Consent for publication}

Not applicable.

\section{Competing interests}

The authors declare that they have no competing interests.

\section{Author details}

${ }^{1}$ Department of Radiation Oncology, Yonsei Cancer Center, Yonsei University College of Medicine, 50-1 Yonsei-ro, Seodaemun-gu, 03722 Seoul, Republic of Korea. ${ }^{2}$ Department of Internal Medicine, Yonsei University College of Medicine, Seoul, Republic of Korea. 
Received: 30 April 2021 Accepted: 14 August 2021

Published online: 23 August 2021

\section{References}

1. Bray F, Ferlay J, Soerjomataram I, Siegel RL, Torre LA, Jemal A. Global cancer statistics 2018: GLOBOCAN estimates of incidence and mortality worldwide for 36 cancers in 185 countries. Cancer J Clin. 2018;68(6):394-424.

2. Fox J, Hunt P. Management of acute bleeding gastric malignancy. Aust N Z J Surg. 1993;63(6):462-5.

3. Savides T, Jensen D, Cohen J, Randall G, Kovacs TG, Pelayo E, et al. Severe upper gastrointestinal tumor bleeding: endoscopic findings, treatment, and outcome. Endoscopy. 1996;28(02):244-8.

4. Sheibani S, Kim J, Chen B, Park S, Saberi B, Keyashian K, et al. Natural history of acute upper $\mathrm{Gl}$ bleeding due to tumours: short-term success and long-term recurrence with or without endoscopic therapy. Aliment Pharmacol Ther. 2013;38(2):144-50.

5. Park H, Ahn JY, Jung HY, Chun JH, Nam K, Lee JH, et al. Can endoscopic bleeding control improve the prognosis of advanced gastric cancer patients?: a retrospective case-control study. J Clin Gastroenterol. 2017;51(7):599-606.

6. Kim YI, Choi IJ, Cho SJ, Lee JY, Kim CG, Kim MJ, et al. Outcome of endoscopic therapy for cancer bleeding in patients with unresectable gastric cancer. J Gastroenterol Hepatol. 2013;28(9):1489-95.

7. Song IJ, Kim HJ, Lee J, Park JC, Shin SK, Lee SK, et al. Clinical outcomes of endoscopic hemostasis for bleeding in patients with unresectable advanced gastric cancer. J Gastric Cancer. 2017;17(4):374-83.

8. Koh KH, Kim K, Kwon DH, Chung BS, Sohn JY, Ahn DS, et al. The successful endoscopic hemostasis factors in bleeding from advanced gastric cancer. Gastric Cancer. 2013;16(3):397-403.

9. Meehan T, Stecker MS, Kalva SP, Oklu R, Walker TG, Ganguli S. Outcomes of transcatheter arterial embolization for acute hemorrhage originating from gastric adenocarcinoma. J Vasc Interv Radiol. 2014;25(6):847-51.

10. Park S, Shin JH, Gwon D-I, Kim HJ, Sung K-B, Yoon H-K, et al. Transcatheter arterial embolization for gastrointestinal bleeding associated with gastric carcinoma: prognostic factors predicting successful hemostasis and survival. J Vasc Interv Radiol. 2017;28(7):1012-21.

11. Chaw CL, Niblock PG, Chaw CS, Adamson DJ. The role of palliative radiotherapy for haemostasis in unresectable gastric cancer: a singleinstitution experience. Ecancermedicalscience. 2014;8:384.

12. Lee $\mathrm{YH}$, Lee JW, Jang HS. Palliative external beam radiotherapy for the treatment of tumor bleeding in inoperable advanced gastric cancer. BMC Cancer. 2017;17(1):541.

13. Hiramoto S, Kikuchi A, Tetsuso H, Yoshioka A, Kohigashi Y, Maeda I. Efficacy of palliative radiotherapy and chemo-radiotherapy for unresectable gastric cancer demonstrating bleeding and obstruction. Int J Clin Oncol. 2018;23(6):1090-4.
14. Eisenhauer EA, Therasse P, Bogaerts J, Schwartz LH, Sargent D, Ford R, et al. New response evaluation criteria in solid tumours: revised RECIST guideline (version 1.1). Eur J Cancer. 2009;45(2):228-47.

15. Health UDo, Services H. Common Terminology Criteria for Adverse Events (CTCAE) version 5.0. Published November 27, 2017.

16. Tey J, Choo BA, Leong CN, Loy EY, Wong LC, Lim K, et al. Clinical outcome of palliative radiotherapy for locally advanced symptomatic gastric cancer in the modern era. Medicine. 2014;93(22):e118.

17. Kondoh C, Shitara K, Nomura M, Takahari D, Ura T, Tachibana H, et al. Efficacy of palliative radiotherapy for gastric bleeding in patients with unresectable advanced gastric cancer: a retrospective cohort study. BMC Palliative Care. 2015;14(1):37.

18. Kawabata H, Uno K, Yasuda K, Yamashita M. Experience of low-dose, short-course palliative radiotherapy for bleeding from unresectable gastric cancer. J Palliat Med. 2017;20(2):177-80.

19. Tey J, Zheng H,Soon YY, Leong CN, Koh WY, Lim K, et al. Palliative radiotherapy in symptomatic locally advanced gastric cancer: a phase II trial. Cancer Med. 2019;8(4):1447-58.

20. Sapienza LG, Ning MS, Jhingran A, Lin LL, Leao CR, da Silva BB, et al. Shortcourse palliative radiation therapy leads to excellent bleeding control: a single centre retrospective study. Clin TransI Radiat Oncol. 2019;14:40-6.

21. Tey J, Soon YY, Koh WY, Leong CN, Choo BA, Ho F, et al. Palliative radiotherapy for gastric cancer: a systematic review and meta-analysis. Oncotarget. 2017;8(15):25797-805.

22. Kim MM, Rana V, Janjan NA, Das P, Phan AT, Delclos ME, et al. Clinical benefit of palliative radiation therapy in advanced gastric cancer. Acta Oncol. 2008:47(3):421-7.

23. Lee JA, Lim DH, Park W, Ahn YC, Huh SJ. Radiation therapy for gastric cancer bleeding. Tumori J. 2009:95(6):726-30.

24. Hashimoto K, Mayahara H, Takashima A, Nakajima TE, Kato K, Hamaguchi T, et al. Palliative radiation therapy for hemorrhage of unresectable gastric cancer: a single institute experience. J Cancer Res Clin Oncol. 2009;135(8):1117-23.

25. Asakura H, Hashimoto T, Harada H, Mizumoto M, Furutani K, Hasuike N, et al. Palliative radiotherapy for bleeding from advanced gastric cancer: is a schedule of 30 Gy in 10 fractions adequate? J Cancer Res Clin Oncol. 2011;137(1):125-30

26. Villanueva C, Colomo A, Bosch A, Concepción M, Hernandez-Gea V, Aracil $C$, et al. Transfusion strategies for acute upper gastrointestinal bleeding. N Engl J Med. 2013;368(1):11-21.

27. Fayers P, Aaronson NK, Bjordal K, Sullivan M. EORTC QLQ-C30 scoring manual: European Organisation for Research and Treatment of Cancer; 1995.

\section{Publisher's Note}

Springer Nature remains neutral with regard to jurisdictional claims in published maps and institutional affiliations.
Ready to submit your research? Choose BMC and benefit from:

- fast, convenient online submission

- thorough peer review by experienced researchers in your field

- rapid publication on acceptance

- support for research data, including large and complex data types

- gold Open Access which fosters wider collaboration and increased citations

- maximum visibility for your research: over 100M website views per year

At $B M C$, research is always in progress.

Learn more biomedcentral.com/submissions 